\title{
Analysis of the roto-cooler air-conditioning system
}

\author{
Yuan Mao Huang \\ Department of Mechanical Engineering, National Taiwan University, Taiwan, \\ Republic of China \\ Received 4 October 1993; revised 17 April 1995
}

\begin{abstract}
The roto-cooler rotary blade air cycle air-conditioning system is simpler and less expensive than conventional vapour compression air-conditioning systems. This study analyses the effects of the unsteady flow on the heat exchanger and the performance of the roto-cooler system. The air properties, effects of the heat exchanger length on the air properties, the cooling capacity, the thermal coefficient of performance and the total coefficient of performance of the system are studied. Numerical results of the specific operating conditions are compared with the available data. The heat exchanger length of the prototype can be reduced significantly without loss of system performance.

(Keywords: roto-cooler; air-conditioning system; elliptical stator; compressor)
\end{abstract}

\section{Analyse du système de conditionnement d'air 'roto-cooler'}

\begin{abstract}
Le système de conditionnement d'air à cycle à air et à compresseur rotatif est plus simple et moins cher que les systèmes classiques à compression de vapeur. Dans ce rapport, on analyse les effets d'un écoulement invariable sur l'échangeur de chaleur et sur la performance du système. On étudie les propriétés de l'air, les effets sur cellesci des dimensions de l'échangeur de chaleur, ainsi que la puissance de refroidissement, les coefficients de performance thermique et global. On compare les résultats numériques des conditions précises de fonctionnement avec les données disponibles. Les dimensions de l'échangeur peut être sensiblement diminuée sans perte de performance du système.

(Mots clés: conditionnement d'air; machine à air; compresseur rotatif; détendeur; conception; performance)
\end{abstract}

Although current vapour refrigeration air-conditioning systems have been well developed, they are complex, heavy and expensive. High-pressure lines and fittings are required. Compression and road vibration can cause leakage of the refrigerant through connections. The refrigerant can also be contaminated by moisture. The temperature of the evaporator should not be allowed to drop below $0^{\circ} \mathrm{C}$, to avoid the water vapour freezing on it. The roto-cooler air-conditioning system is a simpler, less expensive and environmentally protective device, which may challenge current systems. The end view of the roto-cooler system is shown in Figure $1^{1-3}$.

Edwards ${ }^{i}$ used the assumptions of steady and incompressible flow to predict the effects of the geometries and operating conditions on the cooling capacity and coefficient of the performance of the roto-cooler system. In addition, Edwards failed to include an adequate analysis of the effectiveness of the heat exchanger, which was built conservatively. The purpose of this study is to include the effect of unsteady and compressible flow on the heat exchanger and the performance of the system, and to determine the required length of the heat exchanger.

\section{Method of approach}

As the roto-cooler configuration is complex, some assumptions used in the analysis are as follows:

1. The air is a perfect gas under the operating conditions.

2. The air in the compression and expansion sides of the rotor follows the polytropic process.

3. The properties of the air inside the blade segments are uniform.

4. Fluid dynamic effects at the blade tip and the blade slot interface are neglected.

5. No mass of air is accumulated at the inlet or outlet portions of the heat exchanger.

6 . The cross-sectional area of the heat exchanger is constant.

7. The temperature and velocity of the air surrounding the heat exchanger remain constant.

8. The conductivity and the external heat transfer film coefficient of the heat exchanger are constant.

9. The heat exchanger is a straight duct except the inlet and outlet portions.

10. The change of potential energy is negligible.

11. Radiation from the heat exchanger is neglected.

12. The flow inside the heat exchanger is fully developed. 


\begin{tabular}{|c|c|c|c|}
\hline \multicolumn{4}{|c|}{ Nomenclature } \\
\hline$A$ & $\begin{array}{l}\text { Cross-sectional area of heat exchanger } \\
\left(\mathrm{m}^{2}\right)\end{array}$ & $\begin{array}{l}V \\
W\end{array}$ & Blade segment volume $\left(\mathrm{m}^{3}\right)$ \\
\hline$a$ & Sonic speed $\left(\mathrm{m} \mathrm{s}^{-1}\right)$ & $W_{\mathrm{s}}$ & Work $(\mathrm{N} \mathrm{m})$ \\
\hline$c_{p}$ & $\begin{array}{l}\text { Specific heat at constant pressure } \\
\left(\mathrm{J} \mathrm{kg}^{-1} \mathrm{~K}^{-1}\right)\end{array}$ & $\begin{array}{l}x_{\mathrm{s}} \\
x \\
z\end{array}$ & $\begin{array}{l}\text { Distance from heat exchanger inlet }(\mathrm{m}) \\
\text { Number of blades }\end{array}$ \\
\hline$c_{v}$ & $\begin{array}{l}\text { Specific heat at constant volume } \\
\left(\mathrm{J} \mathrm{kg}^{-1} \mathrm{~K}^{-1}\right)\end{array}$ & \multicolumn{2}{|l|}{ Greek letters } \\
\hline$D$ & $\begin{array}{l}\text { Inside hydraulic diameter of heat } \\
\text { exchanger }(\mathrm{m})\end{array}$ & $\beta$ & Coefficient of performance \\
\hline$e$ & Stored energy per unit mass $\left(\mathrm{J} \mathrm{kg}^{-1}\right)$ & $\rho$ & $\begin{array}{l}\text { Density }\left(\mathrm{kg} \mathrm{m}^{-3}\right) \\
\text { Rotational speed }\left(\mathrm{rad} \mathrm{s}^{-1}\right)\end{array}$ \\
\hline$f$ & Friction factor & & \\
\hline$h$ & Enthalpy per unit mass $\left(\mathrm{J} \mathrm{kg}^{-1}\right)$ & \multicolumn{2}{|l|}{ Subscripts } \\
\hline $\begin{array}{l}h_{\mathrm{p}} \\
i\end{array}$ & $\begin{array}{l}\text { Potential energy per unit mass }\left(\mathrm{J} \mathrm{kg}^{-1}\right) \\
\text { Internal energy per unit mass }\left(\mathrm{J} \mathrm{kg}^{-1}\right)\end{array}$ & $1,2,3,4,5$ & Condition in the blade segment volume \\
\hline$M$ & Mass (kg) & $\mathrm{a}$ & Ambient condition at the roto-cooler \\
\hline$n$ & Polytropic process exponent constant & & inlet \\
\hline$P$ & Power $\left(\mathrm{J} \mathrm{s}^{-1}\right)$ & $\mathrm{c}$ & Condition in blade segment or \\
\hline$p$ & Pressure $\left(\mathrm{N} \mathrm{m}^{-2}\right)$ & & compression \\
\hline$Q$ & Heat added $(\mathbf{J})$ & e & Condition at heat exchanger outlet or \\
\hline$Q_{\mathrm{c}}$ & Cooling capacity $\left(\mathrm{J} \mathrm{s}^{-1}\right)$ & & expansion \\
\hline 4 & $\begin{array}{l}\text { Heat transfer rate per unit area } \\
\left(\mathrm{J} \mathrm{s}^{-1} \mathrm{~m}^{-2}\right)\end{array}$ & $\begin{array}{l}\text { ea } \\
\text { f }\end{array}$ & $\begin{array}{l}\text { Condition surrounding heat exchanger } \\
\text { Friction }\end{array}$ \\
\hline $\operatorname{Re}$ & Reynolds number & io & Initial condition at heat exchanger inlet \\
\hline$T$ & Temperature $(\mathrm{K})$ & th & Thermodynamic quantity \\
\hline$t$ & Time $(\mathrm{s})$ & $\mathrm{tt}$ & Total quantity \\
\hline$U$ & $\begin{array}{l}\text { Overall heat transfer coefficient } \\
\left(\mathrm{J} \mathrm{s}^{-1} \mathrm{~m}^{-2} \mathrm{~K}^{-1}\right)\end{array}$ & \multirow{2}{*}{\multicolumn{2}{|c|}{ Superscripts }} \\
\hline$u$ & Velocity $\left(\mathrm{m} \mathrm{s}^{-1}\right)$ & & Time rate \\
\hline
\end{tabular}

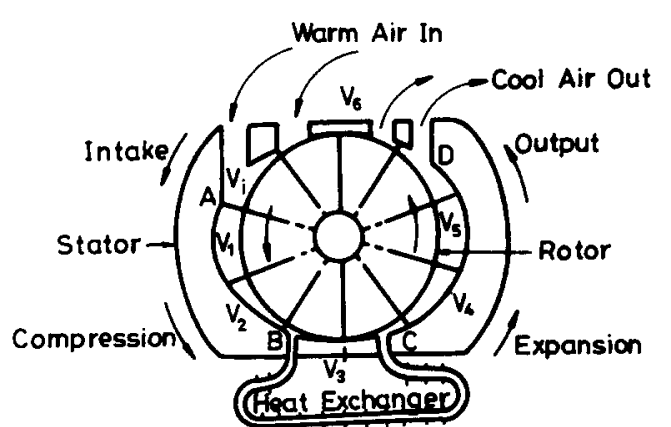

Figure 1 The roto-cooler air-conditioning system

Figure 1 Le système de conditionnement d'air rotatif

13. The specific heats are constant under the operating conditions.

14. The effect of water vapour condensation during the expansion process is neglected.

For counterclockwise rotation of the rotor, air at essentially atmospheric pressure and temperature is drawn from the inlet duct into the blade segment $V_{i}$ as it expands, as shown in Figure 1. When the rear blade of segment $V_{i}$ arrives at point $\mathrm{A}$, the maximum blade segment volume $V_{1}$ is obtained, and the intake process is completed. The air inside the blade segment is assumed to be compressed polytropically with polytropic exponent $n_{\mathrm{cl}}$ to higher pressure and temperature until the leading blade of the blade segment $V_{2}$ arrives at point $\mathrm{B}$. As long as the values of $n_{\mathrm{cl}}$, the rotational speed and the number of blades are given, the air properties inside the blade segment at any location which is a function of time can be determined. The work of compression for the polytropic process from $V_{1}$ to $V_{2}$ is ${ }^{4}$

$W_{\mathrm{cl}}=p_{\mathrm{a}} V_{1} \frac{1}{1-n_{\mathrm{cl}}}\left[\left(\frac{V_{2}}{V_{1}}\right)^{1-n_{\mathrm{cl}}}-1\right]$

Most of the air is then pumped from the blade segment into the heat exchanger, where the air is cooled down by rejecting heat to the surrounding air. The work required is

$W_{\mathrm{c} 2}=\int_{V_{2}}^{V_{3}} p \mathrm{~d} V$

Therefore the total compression work is

$W_{\mathrm{c}}=W_{\mathrm{cl}}+W_{\mathrm{c} 2}$

Taking the compression blade segment as the control volume, the rate of the energy equation for the compression chamber is

$$
\begin{aligned}
& \dot{Q}-\dot{W}+(h \dot{M})_{\text {in }}-(h \dot{M})_{\text {out }}+\left[\frac{1}{2} \dot{M} u^{2}\right]_{\text {in }}-\left[\frac{1}{2} \dot{M} u^{2}\right]_{\text {out }} \\
& +\left[h_{\mathrm{p}} \dot{M}\right]_{\text {in }}-\left[h_{\mathrm{p}} \dot{M}\right]_{\text {out }}=\frac{\mathrm{d}}{\mathrm{d} t}\left[M_{\mathrm{c}}\left(i_{\mathrm{c}}+\frac{1}{2} u_{\mathrm{c}}^{2}+h_{\mathrm{p}}\right)\right]
\end{aligned}
$$

As the volume of the blade segment varies while the air discharges from the blade segment into the heat 
exchanger, the air properties flowing through the heat exchanger vary periodically. The flow is unsteady and is assumed to be one-dimensional. The continuity equation is

$\frac{\partial \rho}{\partial t}+u \frac{\partial \rho}{\partial x}+\rho \frac{\partial u}{\partial x}=0$

If the body force is neglected, the momentum equation can be written as

$u^{2} \frac{\partial \rho}{\partial x}+2 \rho u \frac{\partial u}{\partial x}+\frac{\partial p}{\partial x}+\frac{f \rho u^{2}}{2 D}+u \frac{\partial \rho}{\partial t}+\rho \frac{\partial u}{\partial t}=0$

where the friction factor, $f$, is a function of the surface condition of the heat exchanger and the Reynolds number of the flow ${ }^{5}$. Because the value of the friction factor is uncertain. an empirical formula is assumed ${ }^{6}$ :

$f=0.316 R e^{-0.25}$

As there is no shaft work, the energy equation is ${ }^{7.8}$

$\dot{Q}-\frac{\partial}{\partial x} \rho A u\left(e+\frac{p}{\rho}\right) \mathrm{d} x=\frac{\partial}{\partial t}(\rho A e) \mathrm{d} x$

The overall heat transfer rate, $\dot{Q}$, is given by

$\dot{Q}=\int q \pi D \mathrm{~d} x$

where

$q=U\left(T_{\mathrm{ea}}-T\right)$

and $U$ is the overall heat transfer coefficient, which is assumed to be constant for the temperature range of interest ${ }^{9}$.

Non-dimensional variables are defined as follows:

$\rho^{*}=\frac{\rho}{\rho_{\mathrm{at}}}$

$T^{*}=\frac{\left(T-T_{\mathrm{a}}\right)}{\left(T_{\mathrm{io}}-T_{\mathrm{a}}\right)}$

$t^{*}=\frac{t a_{\mathrm{a}}}{D}$

$u^{*}=\frac{u}{a_{\mathrm{a}}}$

$x^{*}=\frac{x}{D}$

The method of characteristics is used with non-dimensional characteristics as

$\lambda^{*}=\frac{\mathrm{d} x^{*}}{\mathrm{~d} t^{*}}$

The non-dimensional characteristic directions determined from Equations (5), (6) and (8) are

$\lambda^{*}=u^{*}+a^{*}$

$\lambda^{*}=u^{*}-a^{*}$ and

$\lambda^{*}=u^{*}$

The compatibility equations along the characteristic directions (Equations (13), (14) and (15) respectively) are

$$
\begin{aligned}
& \mathrm{d} \rho^{*}+A_{1} \mathrm{~d} u^{*}+A_{2} \mathrm{~d} T^{*}+A_{3} \mathrm{~d} t^{*}=0 \\
& \mathrm{~d} \rho^{*}+B_{1} \mathrm{~d} u^{*}+B_{2} \mathrm{~d} T^{*}+B_{3} \mathrm{~d} t^{*}=0 \\
& \mathrm{~d} \rho^{*}+C_{2} \mathrm{~d} T^{*}+C_{3} \mathrm{~d} t^{*}=0
\end{aligned}
$$

where $A_{1}, A_{2}, A_{3}, B_{1}, B_{2}, B_{3}, C_{2}$ and $C_{3}$ are functions of the air properties and configuration of the system. These equations, which are non-linear ordinary differential equations, can be solved by the finite difference method. The air properties inside the heat exchanger at any location and any time and the heat out of the heat exchanger can then be determined ${ }^{10-14}$

In the meantime, the mass left in the clearance volume $V$. which is bypassing the heat exchanger mixes with the cooled air from the outlet of the heat exchanger. The charging of the expansion blade segment is completed when the rear blade of the blade segment $V_{4}$ just passes the outlet port of the heat exchanger, $C$, as shown in Figure 1 .

Taking the expansion blade segment as the control volume, the mass flowrate into the expansion chamber is

$\dot{M}=u_{\mathrm{e}} \rho_{\mathrm{e}} A$

Assuming that there is no heat transfer during the charging process, the energy equation during the intake process of the expansion blade segment is

$-p_{\mathrm{c}} \mathrm{d} V_{\mathrm{c}}+c_{p} T_{\mathrm{e}} \mathrm{d} M_{\mathrm{c}}+\frac{u_{\mathrm{e}}^{2} \mathrm{~d} M_{\mathrm{c}}}{2}=d\left(c_{,} T_{\mathrm{c}} M_{\mathrm{c}}+\frac{M_{\mathrm{c}} u_{\mathrm{c}}^{2}}{2}\right)$

The expansion work when the air flows polytropically into the expansion blade segment from the outlet of the heat exchanger is

$W_{\mathrm{el}}=\int_{V_{3}}^{V_{4}} p \mathrm{~d} V$

The relatively cool high-pressure air inside the segment $V_{4}$ expands and lowers its temperature and pressure when the rotor rotates. A polytropic expansion with polytropic exponent $n_{\mathrm{e} 3}$ occurs until the leading blade of the blade segment $V_{5}$ arrives at the roto-cooler outlet $\mathrm{D}$. as shown in Figure 1 . This expansion work is

$W_{\mathrm{e} 2}=\frac{p_{4} V_{4}}{1-n_{\mathrm{e} 3}}\left[\left(\frac{V_{4}}{V_{5}}\right)^{n_{\mathrm{e}, 3}-1}-1\right]$

The position of the final outlet of the roto-cooler is chosen to give the air pressure as close as possible to atmospheric pressure. The air is then pumped through 
Table 1 Air properties obtained from the current analysis and from ref. 1

Tableau 1 Propriétés de l'air déterminées par la présente analyse et tirées de la référence I

\begin{tabular}{|c|c|c|c|c|}
\hline \multirow[b]{2}{*}{ Location } & \multicolumn{2}{|c|}{ Temperature $\left({ }^{\circ} \mathrm{C}\right)$} & \multicolumn{2}{|c|}{ Pressure (kPa) } \\
\hline & Current & Ref. 1 & Current & Ref. 1 \\
\hline Inlet of roto-cooler system & 27.2 & 27.2 & 101.3 & 101.3 \\
\hline Complete compression & 113.7 & 113.9 & 303.4 & 300.0 \\
\hline $\begin{array}{l}\text { Compression blade segment before } \\
\text { air flows completely into heat exchanger }\end{array}$ & $113.7-100.8$ & - & $303.4-266.1$ & - \\
\hline Heat exchanger inlet & $110.8-100.6$ & - & $294.4-266.1$ & - \\
\hline Heat exchanger outlet & 32.7 & $32.2-33.3$ & 259.2 & $\ldots-$ \\
\hline $\begin{array}{l}\text { Expansion blade segment before } \\
\text { complete intake process }\end{array}$ & $113.3-36.6$ & - & 259.2 & - \\
\hline
\end{tabular}

Table 2 Performance of the roto-cooler system obtained from the current analysis and from ref. 1

Tableau 2 Performance du système 'roto-cooler', déterminée par la présente analyse et tirés de la référence 1

\begin{tabular}{|c|c|c|}
\hline & Current & Ref. 1 \\
\hline Compression power input $\left(\mathrm{kJ} \mathrm{h}^{-1}\right)$ & 25120 & - \\
\hline Expansion power output $\left(\mathrm{kJ} \mathrm{h}^{-1}\right)$ & 19614 & - \\
\hline Thermal power $\left(\mathrm{kJ} \mathrm{h}^{-1}\right)$ & 5506 & 一 \\
\hline Friction power $\left(\mathrm{kJ} \mathrm{h}^{-1}\right)$ & 9392 & 9284 \\
\hline Total power $\left(\mathbf{k J ~ h}^{-1}\right)$ & 15004 & - \\
\hline Cooling capacity $\left(\mathrm{kJ} \mathrm{h}^{-1}\right)$ & 5971 & 5686 \\
\hline $\begin{array}{l}\text { Heat transfer rate out of the } \\
\text { compression side of the } \\
\text { stator }\left(\mathrm{kJ} \mathrm{h}^{-1}\right)\end{array}$ & 19191 & - \\
\hline $\begin{array}{l}\text { Heat transfer rate into the } \\
\text { expansion side of the stator } \\
\left(\mathrm{kJ} \mathrm{h}^{-1}\right)\end{array}$ & 8249 & - \\
\hline $\begin{array}{l}\text { Net heat transfer rate out of } \\
\text { the stator }\left(\mathrm{kJ} \mathrm{h}^{-1}\right)\end{array}$ & 10942 & - \\
\hline $\begin{array}{l}\text { Heat transfer rate out of the heat } \\
\text { exchanger }\left(\mathrm{kJ} \mathrm{h}^{-1}\right)\end{array}$ & 9568 & - \\
\hline Thermal coefficient of performance & 1.09 & - \\
\hline Total coefficient of performance & 0.40 & $0.42-0.45$ \\
\hline
\end{tabular}



Figure 2 The variation range of the air temperature inside the heat exchanger

Figure 2 La gamme de températures de l'air à l'intérieur de l'échangeur de chaleur

the outlet duct into the space being cooled. Thus the work from the air to the blade is close to zero and it may be neglected. Therefore, the total expansion work is

$W_{\mathrm{e}}=W_{\mathrm{e} 1}+W_{\mathrm{e} 2}$

The thermodynamic work per blade segment required to operate the roto-cooler system is

$W_{\mathrm{th}}=W_{\mathrm{c}}-W_{\mathrm{e}}$

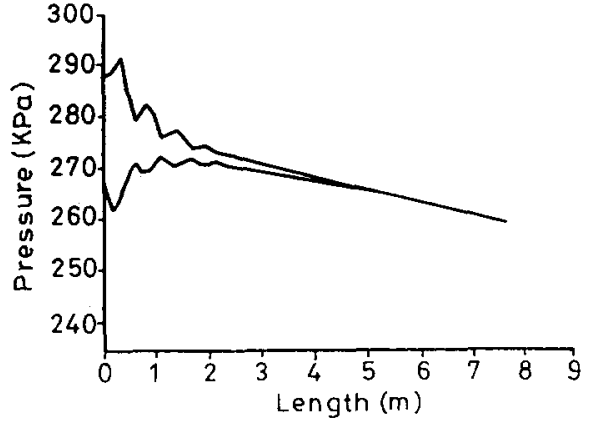

Figure 3 The variation range of the air pressure inside the heat exchanger

Figure 3 La gamme de pressions de l'air à l'intérieur de l'échangeur de chaleur

The thermodynamic power requirement, $P_{\mathrm{th}}$, is

$P_{\mathrm{th}}=W_{\mathrm{th}} \frac{z \omega}{2 \pi}$

where $z$ is the number of blades and $\omega$ is the rotational speed. The cooling capacity of the system is defined as

$\dot{Q}_{\mathrm{c}}=\dot{M} c_{p}\left(T_{1}-T_{5}\right)$

where $T_{1}$ and $T_{5}$ are the inlet temperature and the final outlet temperature of the system respectively. The thermal coefficient of performance is defined as

$\beta_{\mathrm{th}}=\frac{Q_{\mathrm{c}}}{P_{\mathrm{th}}}$

If the friction power of the roto-cooler system, $P_{\mathrm{f}}$, is included, the total coefficient of performance can be determined:

$\beta_{\mathrm{tt}}=\frac{Q_{\mathrm{c}}}{P_{\mathrm{th}}+P_{\mathrm{f}}}$

\section{Results}

The geometry and operating conditions used are as follows: stator width $0.1524 \mathrm{~m}$; length of stator major axis and stator minor axis $0.1524 \mathrm{~m}$ and $0.1168 \mathrm{~m}$ respectively; blade thickness $0.0476 \mathrm{~m}$; rotor-stator clearance $0.0000762 \pm 0.0000254 \mathrm{~m}$; ambient air temperature and pressure $27.22^{\circ} \mathrm{C}$ and $101.3 \mathrm{kPa}$ respectively; and relative humidity $25 \%$. The materials of the stator, rotor and blades are vespel and all the friction coefficient 


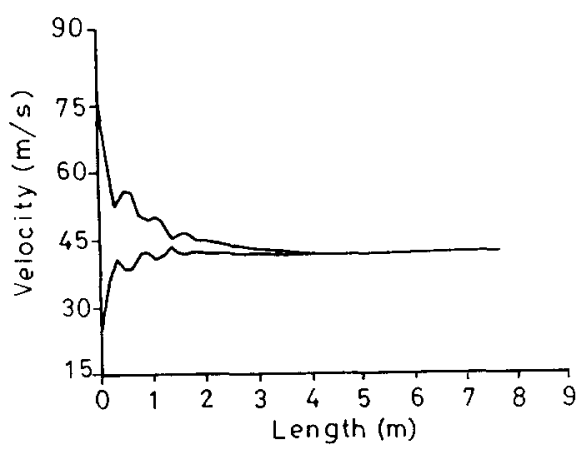

Figure 4 The variation range of the air velocity inside the heat exchanger

Figure 4 La gamme de vitesses de l'air à l'intérieur de l'échangeur de chaleur

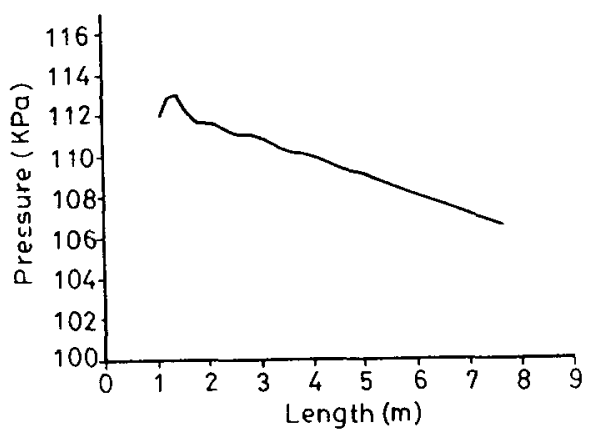

Figure 5 Effect of the heat exchanger length on the air pressure at the final outlet of the system

Figure 5 Effet de la longueur de l'échangeur de chaleur sur la pression de l'air à la sortie définitive du système

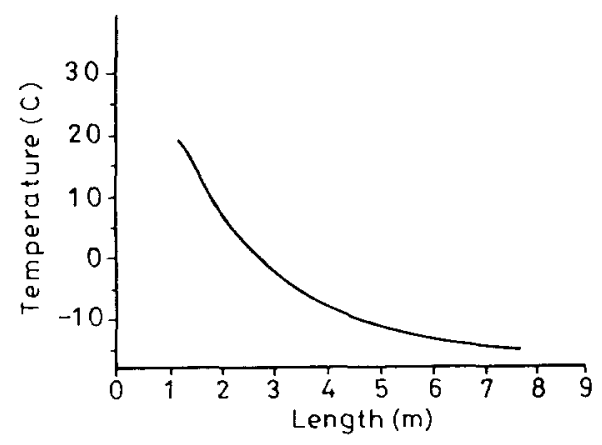

Figure 6 Effect of the heat exchanger length on the air temperature at the final outlet of the system

Figure 6 Effet de la longueur de l'échangeur de chaleur sur la température de l'air à la sortie définitive du système

of the material is 0.11 . The thermal conductivities of air and the heat exchanger used for analysis are $0.0099 \mathrm{~J} \mathrm{~s}^{-1} \mathrm{~m}^{-1} \mathrm{~K}^{-1}$ and $117.49 \mathrm{~J} \mathrm{~s}^{-1} \mathrm{~m}^{-1} \mathrm{~K}^{-1}$ respectively. The inside diameter, wall thickness and length of the heat exchanger are $19.1 \mathrm{~mm}, 1.55 \mathrm{~mm}$ and $7.62 \mathrm{~m}$ respectively. The values of $n_{\mathrm{c} 1}$ and $n_{\mathrm{e} 3}$ are determined to be 1.30 and 1.35 respectively, based on a comparison of the calculated results with the experimental data ${ }^{1}$. It is assumed that the effects of water vapour condensation during expansion and the reduction in air volume after condensation are neglected. The current calculated results and the data obtained from Edwards ${ }^{1}$ are

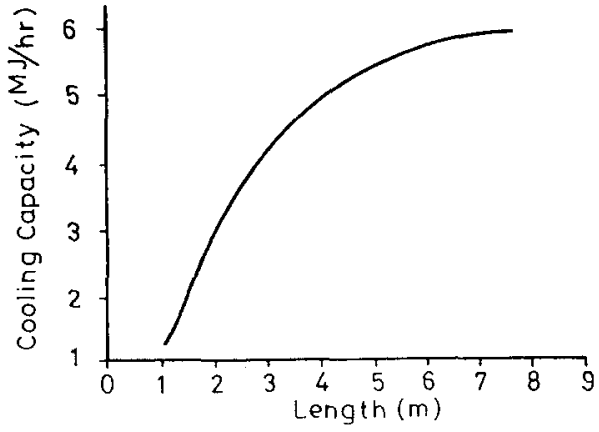

Figure 7 Effect of the heat exchanger length on the cooling capacity of the system

Figure 7 Effet de la longueur de l'échangeur de chaleur sur la puissance de refroidissement du système

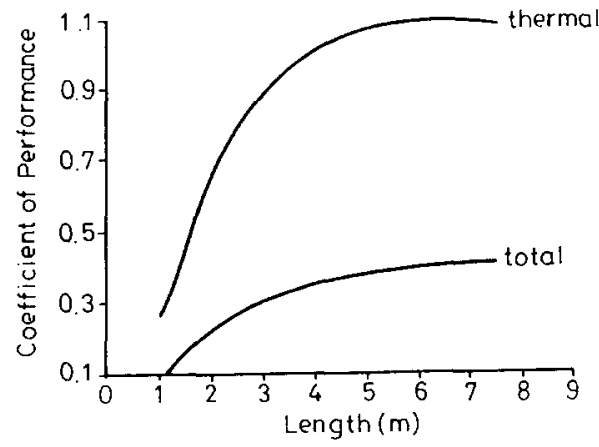

Figure 8 Effect of the heat exchanger length on the thermal coefficient of performance and the total coefficient of performance of the system Figure 8 Effet de la longueur de l'échangeur de chaleur sur les coefficients de performance thermique et global du systeme

summarized in Tables 1 and 2 for comparison.

The variation ranges of the air temperature, pressure and velocity inside the heat exchanger versus the location along the heat exchanger are shown in Figures 2, 3 and 4 respectively. The effects of the heat exchanger length on the air pressure and temperature at the final outlet of the system are shown in Figures 5 and 6 respectively. Also, the effects of the heat exchanger length on the cooling capacity, the thermal coefficient of performance and the total coefficient of performance of the system are shown in Figures 7 and 8 respectively.

\section{Discussion}

The calculated variation ranges of the air velocity, pressure and temperature in the heat exchanger may be as large as 129,10 and $3 \%$ of the respective mean values. As the air properties change during the periodic motion of the blades, the effects of unsteady flow exist.

The calculated temperature and pressure of the air at various locations and the performance of the system are compared and show good agreement with the data obtained by Edwards ${ }^{1}$. Comparing the calculated heat transfer rate out of the heat exchanger from Equation (9), $9568 \mathrm{~kJ} \mathrm{~h}^{-1}$, with the difference of the air enthalpy at the inlet and the outlet of the heat exchanger, $9513 \mathrm{~kJ} \mathrm{~h}^{-1}$, shows that the calculated result is correct.

Various lengths of the heat exchanger up to $7.62 \mathrm{~m}$ are investigated. The temperature and velocity of the air do 
not change appreciably for heat exchangers longer than $5.08 \mathrm{~m}$. The temperature profile along the heat exchanger is comparable with that of the experimental model. It also shows that the heat out of the heat exchanger, the cooling capacity, the thermal coefficient of performance and the total coefficient of performance of the rotocooler system do not increase appreciably for heat exchangers longer than $5.08 \mathrm{~m}$. The thermal coefficient of performance begins to decrease gradually for heat exchangers longer than $6.35 \mathrm{~m}$. As the length of the heat exchanger increases, the air pressure at the heat exchanger outlet decreases because of the friction effect. Therefore the recovered work of expansion decreases and the thermal power required increases. The air temperature at the exit of the roto-cooler system is $-15.2{ }^{\circ} \mathrm{C}$. Further analysis is worthwhile to determine the water vapour condensation and reduction of the air volume during the expansion process. Atmospheric air can be used to mix with this cold air to reduce the effect of water vapour condensation.

\section{Conclusion}

The prototype roto-cooler system delivers the required design cooling capacity, but the coefficient of performance of the system is low. The calculated results prove that the prototype heat exchanger was designed conservatively. Friction losses are a large fraction of the power required to drive the roto-cooler system. Mechanical friction and compression losses for the roto-cooler may be reduced by design improvements.

State point data of the prototype obtained from experiments are used to determine the best polytropic exponents in the analytical model. The results are limited to conditions similar to those used in the tests of the prototype. However, the performance is not sensitive to the choice of these exponents for the range of interest. Therefore, the mathematical model could be used to predict performance of the system with a wide range of operation conditions. A heat exchanger $5.08 \mathrm{~m}$ long, which is $2.54 \mathrm{~m}$ shorter than that of the prototype, can be used without loss of system performance.

\section{Acknowledgment}

The author thanks the National Science Council of the Republic of China for Grant NSC82-0401-E-002-425 to complete this publication.

\section{References}

1 Edwards, T. C. A rotary blade open reversed Brayton cycle air conditioning and refrigeration system $P h D$ Thesis School of Mechanical Engineering, Purdue University, Lafayette, IN (1970)

2 Edwards, T. C., McDonald, A. T. ROVACS: a new rotary blade air-cycle air conditioning and refrigeration system $S A E$ paper 720079 (1972)

3 Edwards, T. C. The ROVAC automative air conditioning system SAE paper 750403 (1975)

4 Huang, Yuan Mao Study of fluid properties in the compressor with an elliptical stator ASME Pressure Vessels and Piping (1991) $21913-18$

5 Kraus, A. D. Analysis of extended surface $A S M E J$ Heat Transfer (1988) $1101071-1081$

6 Days, W. M. Crawford, M. E. Convective Heat and Mass Transfer 2nd edn, McGraw-Hill, New York (1980)

7 Lundgren, T. S., Sparrow, E. M., Starr, J. B. Pressure drop due to the entrance region in ducts of arbitrary cross section $A S M E$ $J$ Basic Eng (1964) 86 620-626

8 Rindt, C. C. M., Steenhoven, A. A. van, Janssen, J. D., Vossers, G. Unsteady entrance flow in a 90 deg Curved Tube $J$ Fluid Mech (1991) $226445-474$

9 Holman, J. P. Heat Transfer McGraw-Hill, New York (1963)

10 Huang, Yuan Mao Study of unsteady flow in the heat exchanger by the method of characteristics ASME J Pressure Vessel Technol (1992) 114 459-463

11 Gilbert, D. E., Leay, R. W., Barrow, H. Theoretical analysis of forced laminar convection heat transfer in the entrance region of an elliptic duct Int J Heat Mass Transfer (1973) 16 1501-1503

12 Rudinger, G. Nonsteady Duct Flow: Wave Diagram Analysis Dover Publications, New York (1969)

13 Abdel-Wahed, R. M., Attia, A. E., Hifni, M. A. Experiments on laminar flow and heat transfer in an elliptical duct $I n t J$ Heat Mass Transfer (1984) 27 2397-2413

14 Dunwoody, N. T. Thermal results of forced heat convection through elliptical ducts ASME J Appl Mech (1962) 1965-1970 